\title{
A (HÁ) SAÚDE MENTAL DO PROFESSOR DE PSICOLOGIA
}

Artigo teórico/empírico

\author{
The (There is) Mental Health of the Psychology Teacher
}

La Santé Mentale du Professeur de Psychologie

A (Hay) Salud Mental del Profesor de Psicología

\begin{abstract}
Cristiane de Carvalho Guimarães ${ }^{1}$
OCIRD: http://orcid.org/0000-0003-4026-058X

Universidade Estácio de Sá, Rio de Janeiro, Rio de Janeiro, Brasil. Psicóloga, Mestre em Psicologia pela Pontifícia Universidade Católica do Rio de Janeiro. Doutoranda em Educação na Universidade Estácio de Sá. Professora e pesquisadora da UNESA-RJ
\end{abstract}

Larissa Diniz de Pontes ${ }^{2}$

ORCID: http://orcid.org/0000-0001-8879-1983

Universidade Estácio de Sá, Rio de Janeiro, Rio de Janeiro, Brasil.

Graduanda em Psicologia pela Universidade Estácio de Sá. Bolsista de Iniciação Científica e membro do Núcleo de Pesquisa em Atenção Psicossocial (NUPAP), Membro do Grupo de Estudos em Psicologia Hospitalar no

Hospital Federal de Ipanema.

Flaviany Ribeiro da Silva ${ }^{3}$

ORCID http://orcid.org/0000-0002-4855-3304

Universidade Estácio de Sá, Rio de Janeiro, Rio de Janeiro, Brasil. Doutora em Saúde da Criança e da Mulher pelo Instituto Fernandes Figueira - Fundação Oswaldo Cruz com cotutela em Centro de Estudos Sociais (Universidade de Coimbra). Mestre em Psicologia Social pela Universidade do Estado do Rio de Janeiro. Professora e pesquisadora na UNESA-RJ.

Isabela Ferreira Rocha Nunes ${ }^{4}$

ORCID: http://orcid.org/0000-0003-0275-3009

Universidade Estácio de Sá, Rio de Janeiro, Rio de Janeiro, Brasil. Graduanda em Psicologia pela UNESA, Bolsista de iniciação científica UNESA, Membro do NUPAP (Núcleo de Pesquisas em Atenção Psicossocial), Membro do GPAP (Grupo de Pesquisas em Avaliação Psicológica), Membro do Grupo de Estudos em Psicologia Hospitalar no HFI (Hospital Federal de Ipanema).

\section{Resumo}

O estudo da saúde mental do docente tem despertado interesse na comunidade científica. A pressão social do trabalhador da área da educação tem crescido progressivamente e a necessidade de demonstrar um bom desenvolvimento em seu trabalho em consonância com as condições de trabalho, resultam em desgaste psicológico, físico e emocional. A presente pesquisa, desenvolvida com o apoio do Programa de Iniciação Científica da Universidade Estácio de Sá, teve como objetivo verificar a relação entre o processo de trabalho do docente e as condições sob as quais ele se desenvolve, a fim de verificar sua ligação com o surgimento de sofrimento mental dos professores do curso de graduação em psicologia do Campus Nova Iguaçu da referida Universidade. Foram realizadas entrevistas semiestruturadas e aplicação do instrumento de autopreenchimento Self Reporting Questionnaire (SRQ-20), validado para o Brasil há mais de 20 anos e revalidado em 2008. O estresse foi apontado como sintoma prevalente, bem como o cansaço. As condições de trabalho corroboram para o surgimento de afecções otorrinolaringológicas, osteomusculares, doenças psicossomáticas e, em um dos casos,

\footnotetext{
${ }^{1}$ cris.cguima@gmail.com

2 larissadpontes@outlook.com

3 flaviany.ribeiro@gmail.com

${ }^{4}$ isarochanunes@gmail.com
}

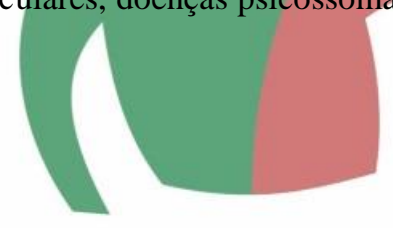


o aparecimento de doença autoimune. Espera-se que esses resultados impulsionem o planejamento de intervenções eficazes no que se refere ao trabalho docente no ensino superior.

Palavras-chave: Saúde mental; Trabalho docente; Psicologia.

\begin{abstract}
The study of the mental health of the teacher has aroused interest in the scientific community. The social pressure of the education worker has grown progressively and the need to demonstrate a good development in their work in line with the working conditions, result in psychological, physical and emotional wear and tear. This research, developed with the support of the Scientific Initiation Program of the Estácio de Sá University, aimed to verify the relationship between teachers' work process and the conditions under which it develops, in order to verify its connection with the emergence of mental suffering of the professors of the undergraduate course in psychology of the Nova Iguaçu campus of the mentioned University. Semi-structured interviews were conducted and the selfreport Self-Reporting Questionnaire (SRQ-20) was applied, validated for Brazil for more than 20 years and revalidated in 2008. Stress was indicated as a prevalent symptom, as well as fatigue. The working conditions support to the development of diseases, otorhinolaryngological, musculoskeletal, psychosomatic and, in one case, the onset of autoimmune disease. It is hoped that these results will lead to the planning of effective interventions for teaching work in higher education.
\end{abstract}

Key words: Mental Health; Teaching work; Psychology.

\title{
Résumé
}

L'étude de la santé mentale de l'enseignant a suscité l'intérêt de la communauté scientifique. La pression de l'assistante sociale dans le domaine de l'éducation, il a grandi sur une base continue et la nécessité de montrer une bonne performance dans leur travail, en conformité avec les conditions du travail, résultant de l'usure et à la déchirure sur le plan psychologique, physique et affectif. Cette recherche, développée avec le soutien du Programme d'Initiation Scientifique de l'Université Estácio de Sá, visait à vérifier la relation entre le processus de travail des enseignants et les conditions dans lesquelles il évolue, afin de vérifier son lien avec l'émergence de la souffrance mentale des les professeurs du cours de premier cycle en psychologie du campus Nova Iguaçu de l'université mentionnée. Des entretiens semi-structurés ont été réalisés et le questionnaire d'autodéclaration SRQ20 a été appliqué, validé pour le Brésil pendant plus de 20 ans et revalidé en 2008. Le stress était indiqué comme un symptôme prévalent, ainsi que la fatigue. Les conditions de travail favorisent le développement de maladies otorhino-laryngologiques, musculo-squelettiques, psychosomatiques et, dans un cas, de maladies auto-immunes. On espère que ces résultats permettront de planifier des interventions efficaces pour l'enseignement dans l'enseignement supérieur.

Mots-clés: Santé mentale; Travail d'enseignement; Psychologie.

\section{Resumen}

El estudio de la salud mental del profesor ha despertado interés en la comunidad científica. La presión social del trabajador de la educación ha crecido constantemente y la necesidad de demostrar un buen desarrollo en su trabajo en línea con las condiciones de trabajo, resulta en desgaste psicológico, físico y emocional. La presente investigación, desarrollada con el apoyo del Programa de Iniciación Científica de la Universidad Estácio de Sá, tuvo como objetivo verificar la relación entre el proceso de trabajo del docente y lạs condiciones en las que se desarrolla, para verificar su conexión con el surgimiento del sufrimiento mental de los profesores del curso de graduación en psicología del Campus Nova Iguaçu de la mencionada Universidad. Se realizaron entrevistas semiestructuradas y se aplicó el cuestionario de autoinforme (SRQ-20), valido para Brasil por más de 20 años y se revalidó en 2008. El estrés se indicó como un síntoma prevalente, así como la fatiga. Las condiciones de trabajo corroboran la aparición de enfermedades otorrinolaringológicas, musculoesqueléticas, psicosomáticas y, en un caso, autoinmunes. Se espera que estos resultados conduzcan a la planificación de intervenciones efectivas para el trabajo docente en la educación superior.

Palabras clave: Salud mental; Trabajo docente; Psicología.

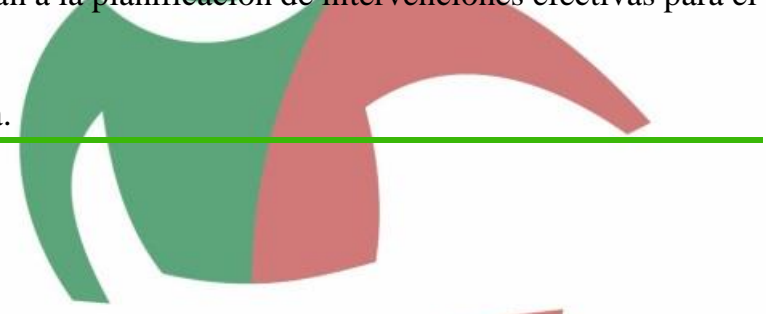




\section{INTRODUÇÃO}

A saúde mental do professor tem despertado interesse da comunidade científica, visto que tal profissão é considerada uma das mais estressantes e desgastantes na atualidade. Esta preocupação provém do fato de que as transformações no contexto social têm aumentado as demandas que são impostas ao trabalhador da área de educação de forma significativa. A pressão social que o professor tem vivenciado está relacionada com a "sociedade do conhecimento", que se orienta para uma classe de pessoas especialistas capazes de combinar conhecimentos, ensinar, aprender e fazer avançar o conhecimento em forma de ação. Nesta sociedade a riqueza é produto do conhecimento, matéria-prima básica da economia onde o docente é personagem principal (Sterwart, 1998 como citado em Cavichioli, 2010, pp. 143144).

A administração do conhecimento e a programação da inovação são capazes de produzir no docente a necessidade de demonstrar um bom desenvolvimento em seu trabalho, podendo ocasionar desgaste psicológico, físico e emocional, levando a quadros de depressão, Síndrome de Burnout (SB) e sentimentos de insatisfação e/ou inaptidão profissional. Pesquisas recentes apresentam estudos sobre o adoecer mental do docente, mencionando exaustão, depressão, insônia e outros (Diehl \& Marin, 2016; Pinto, 2015). Estudos sobre o adoecer psíquico dos professores do curso de graduação em Psicologia, entretanto, são inexistentes. Portanto houve um interesse pelas questões relacionadas à saúde mental deste docente e as repercussões da ausência ou instabilidade da mesma em correlação ao desenvolvimento do trabalho e estabelecimento de vínculo com os alunos.

Diante disto, o presente estudo teve como objetivo verificar a relação entre o processo de trabalho do docente, as condições sob as quais ele se desenvolve e o possível sofrimento mental dos professores do curso de graduação em psicologia do campus Nova Iguaçu da Universidade Estácio de Sá (UNESA), visando à análise da compreensão dos docentes em relação as suas vivências no ambiente universitário, como também o estabelecimento de vínculos com seus alunos e colegas de trabalho.

\section{O trabalho docente}

A recomendação da Organização Internacional do Trabalho (OIT) e da Organização das Nações Unidas para a Educação, a Ciência e a Cultura (UNESCO) relativa ao Estatuto do 
Pessoal Docente foi adotada em 05 de outubro de 1966 numa conferência especial intergovernamental convocada pela UNESCO, Paris, em articulação com a OIT (1984) e estabelece os direitos e responsabilidades dos professores e os padrões internacionais para a sua preparação inicial e formação contínua, recrutamento, emprego e condições de ensinoaprendizagem. Apresenta também recomendações para a participação dos professores nas decisões educativas através de consultas e negociações com as autoridades da educação. A OIT definiu as condições de trabalho para os professores ao reconhecer o lugar central que estes ocupam na sociedade, considerando que são os responsáveis pelo preparo dos cidadãos para a vida. E é a própria OIT que informa que ensinar é geralmente uma atividade estressante, que se tornou desgastante ao longo de sua história, com repercussões evidentes na saúde física, mental e no desempenho profissional (Reis, Araújo, Carvalho, Barbalho, \& Silva, 2006).

As mudanças que têm ocorrido em relação à função do professor, como a fragmentação do seu trabalho e a complexidade das demandas que lhe são impostas, coincidem com um processo histórico de rápida transformação do contexto social (Léon, 2011). Em função disso, ampliam-se as responsabilidades e exigências sobre esse profissional, de modo que ele precisa apresentar, além das competências pedagógicas, habilidades sociais e emocionais (Jenennings \& Greenberg, 2009).

O papel do professor ultrapassou a mediação do processo de conhecimento do aluno. Ampliou-se a missão do profissional para além da sala de aula a fim de garantir uma articulação entre a escola (academia) e a comunidade. O professor além de ensinar, deve participar da gestão e do planejamento escolar, o que significa uma dedicação mais ampla (Gasparini, Barreto, \& Assunção, 2005).

Estudos também apontam que as repercussões negativas na saúde mental do professor também podem ser causadas pelo intenso envolvimento emocional com os problemas dos alunos, como também a desvalorização e falta de motivação relacionada ao trabalho. Além disso, o docente também lida com classes numerosas, falta de tempo para descanso, pois o trabalho na maioria das vezes vai para além da sala de aula, como por exemplo, correções de provas e planejamento de conteúdo para as aulas (Neves \& Silva, 2006 como citado em Diehl \& Marin, 2016, p. 65).

Essas múltiplas tarefas impostas ao professor, como também a ausência de controle sobre o próprio trabalho contribui de forma significativa para elevados níveis dos hormônios do estresse, trazendo prejuízos para a saúde do docente (Reis et al., 2006). Altos níveis de estresse também trazem como consequência uma baixa produtividade do docente em sala de aula. 
O stress excessivo é capaz de produzir um número grande de consequências para o indivíduo em si, para sua família, a empresa para a qual trabalha e a comunidade onde vive. No âmbito psicológico e emocional do ser humano, o stress excessivo produz cansaço mental, dificuldade de concentração, perda de memória imediata, apatia e indiferença emocional. A produtividade sofre quedas e a criatividade fica prejudicada. Autodúvidas começam a surgir em virtude da percepção do desempenho insatisfatório. Crises de ansiedade e humor depressivo se seguem. A libido fica reduzida e os problemas de ordem física se fazem presentes. Nestas condições, a qualidade de vida sofre um dano bastante pronunciado e frequentemente os pacientes, nesta situação, relatam "vontade de fugir de tudo" (Lipp, 2008, p. 20).

Dada sua importância, a saúde mental do professor é tema que adquire crescente relevância e tem sido alvo de preocupação por parte de profissionais, gestores e entidades sindicais e governamentais. Em estudo recente, Cortez, Souza, Amaral e Silva (2017) apontam um retrato geral da saúde no trabalho docente e inferem o seguinte quadro: a intensificação da jornada de trabalho e a desarticulação das políticas que legislam sobre o tema perpetuam a construção de um ciclo de adoecimento físico e mental que implica sofrimento, desestruturação psíquica e problemas vocais aos professores.

Em especial há um destaque nos estudos para a saúde mental do docente, tendo em vista as repercussões da ausência ou instabilidade da mesma nas relações com os discentes e no processo de ensino. Considerando que a saúde e a educação são condições fundamentais para o desenvolvimento humano e social, é importante atentar que esses profissionais precisam de competência pedagógica, social e emocional para estimular a construção crítica dos indivíduos para que aprendam a ser e a conviver na sociedade como sujeitos conscientes, reflexivos e participativos, mas para isso é fundamental que também estejam física e mentalmente saudáveis.

Na busca por artigos em periódicos em português (Scielo, BVS e Pepsic) e repositórios de teses e dissertações de mestrado e doutorado das Universidades brasileiras, entretanto, não há evidência de nenhum trabalho sobre a saúde mental dos professores de cursos de graduação em Psicologia. O que chama a atenção, tendo em vista que são estes os professores que ensinam os conceitos de saúde mental e seu manejo e tratamento a novos profissionais de saúde. Há trabalhos sobre a saúde mental dos professores universitários da área de saúde, inclusive apontando a existência de transtornos mentais comuns ou menores que são conjuntos de manifestações de mal-estar psíquico, de caráter inespecífico, com repercussões fisiológicas e psicológicas que podem gerar limitações (Cerchiari, Caetano, \& Faccenda, 2005). E há alguns outros indicando o docente universitário de qualquer curso como integrante um grupo de risco para o desenvolvimento da Síndrome de Burnout, distúrbio psíquico que se caracteriza pelo 
esgotamento físico, mental e psíquico do indivíduo como uma resposta ao estresse laboral crônico, característica dos profissionais que trabalham com pessoas (Costa, Gil-Monte, Possobon, \& Ambrosano, 2013).

No campo de investigação em questão, o trabalho do docente do curso de graduação em psicologia do campus Nova Iguaçu da Universidade Estácio de Sá, se enquadra na escassez de produções científicas sobre o mesmo.

\section{A psicologia na UNESA e o trabalho docente}

O Curso de Psicologia da Universidade Estácio de Sá começou suas atividades no então campus Rebouças (hoje João Uchôa) em 1988, a partir do decreto n ${ }^{\circ} 95.741$ de 19 de fevereiro de 1988 (D.O.U. 22/02/1988). O Curso foi reconhecido pela Portaria Ministerial/MEC n 1942 , de 25 de outubro de 1991, publicada no Diário Oficial da União de 29 de outubro de 1991.

A motivação de sua implantação e ampliação atendeu inicialmente às necessidades decorrentes dos contextos regionais. Logo o curso estendeu suas atividades ao campus Barra em 1995, Nova Friburgo em 1996, Resende em 1997, Campos de Goytacazes em 1998, Niterói e Méier em 2000, Santa Cruz em 2001, Taquara em 2002, Ilha do Governador em 2004, Norte Shopping em 2007, Macaé em 2009, Nova Iguaçu em 2010, Sulacap em 2012 e Petrópolis em 2013.

Esta multiplicidade de campi é sustentada por um Projeto Pedagógico do curso que atende a realidade desses municípios e bairros, respeitando os princípios de organicidade e unicidade e buscando assim, a garantia da mesma qualidade a todos os alunos do Curso de Psicologia da Universidade Estácio de Sá. Tal organicidade, reflexo da preocupação em garantir ao alunado o oferecimento de um curso uno, não inviabiliza que se considerem as expectativas e as necessidades da clientela local, buscando oferecer à mesma, atividades acadêmicas de pesquisa e de extensão, bem como os estágios curriculares que são desenvolvidos através de convênios com as instituições locais.

Há nove anos o curso de Psicologia funciona na unidade Nova Iguaçu. Há nove anos que a dinâmica das relações envolvendo professores, alunos, coordenadores, entres outros colaboradores no campus vem acontecendo, mas nenhuma pesquisa foi realizada com o intuito de investigar a saúde mental, considerando a produção da subjetividade neste contexto. Sabendo que o docente se enquadra como parte central nas relações que vão sendo estabelecidas, é válido ressaltar as variáveis que os circundam: a sobrecarga de trabalho, dificuldades de 
relacionamento com colegas e alunos, cobrança no desempenho, más condições de trabalho, falta de reconhecimento, entre outras; e o quanto elas afetam a saúde mental do mesmo.

Destacando que os professores da graduação em Psicologia são profissionais da saúde mental, que devem ensinar seus alunos a lidarem com o sofrimento psíquico e emocional, ou seja, com a saúde mental, ao mesmo tempo em que sofrem a ação das transformações no campo de atuação da educação.

\section{MÉTODOS}

Após uma busca por artigos brasileiros e em repositórios de teses e dissertações de mestrado e doutorado (Catálogo de Teses e dissertações - CAPES; Biblioteca Digital Brasileira de Teses e Dissertações - BDTD) durante o período de agosto a setembro de 2018, verificamos a inexistência de produções científicas específicas sobre a saúde mental do docente da graduação em psicologia. Este dado explicita uma enigmática e intrigante lacuna, uma vez que são estes os profissionais responsáveis por ensinar aos seus discentes a lidarem com o sofrimento psíquico e emocional, isto é, com a saúde mental, ao mesmo tempo em que está cercado dos fatores potencialmente desencadeantes de estresse no seu campo da educação. Diante disso, optamos por efetivar a pesquisa com os professores do curso de graduação em Psicologia da Universidade Estácio de Sá, Campus Nova Iguaçu, localizado no estado do Rio de Janeiro, uma vez que há uma precariedade de pesquisas focadas na população da Baixada Fluminense. Cabe ressaltar, além disso, que os autores são também professores e alunos do referido curso, o que acrescenta um interesse especial pelo tema.

Trata-se de uma pesquisa exploratório-descritiva, de abordagem qualitativa/quantitativa realizada no período de agosto de 2018 a junho de 2019. Participaram desta pesquisa 22 professores do curso de graduação em Psicologia da referida universidade. Todos responderam ao instrumento psicológico de autopreenchimento Self-Reporting Questionnaire (SRQ-20) após realizarem uma entrevista semiestruturada. As entrevistas e a aplicação do instrumento foram realizadas nas dependências do campus.

A entrevista semiestruturada foi composta por questões sobre atuação na universidade (tempo de docência, formação inicial e pós-graduaçâo, título atual e idade), condições de trabalho (infraestrutura do Campus e Avaliação Institucional), relacionamentos (dificuldades e facilidades com os colegas de trabalho, gestores do Campus e alunos), autoavaliação como professor (expectativas alcançadas e expectativas a serem alcançadas) e adoecimento mental 
e/ou emocional relacionado ao trabalho como professor (sintomas, incidência e comportamentos saudáveis para manutenção da saúde).

Como instrumento psicológico, foi utilizado o instrumento de autopreenchimento SelfReporting Questionnaire (SRQ), que é um instrumento de rastreamento psiquiátrico proposto por Harding et al. (1980). O SRQ está recomendado pela Organização Mundial de Saúde (OMS) para estudos comunitários e em atenção básica à saúde, principalmente nos países em desenvolvimento, em função de facilidade de uso e custo reduzido. Este instrumento foi desenvolvido inicialmente por uma versão com 30 questões (SRQ-30), sendo 20 sobre sintomas psicossomáticos para rastreamento de transtornos não-psicóticos, quatro para rastreamento de transtornos psicóticos, uma para rastreamento de convulsões do tipo tônico-clônica e cinco questões para rastreamento de transtorno por uso de álcool (Gonçalves, Stein, \& Kapczinski, 2008).

A versão utilizada para esta pesquisa foi o SRQ-20, que consiste em uma versão reduzida do SRQ-30, com 20 questões pertinentes ao rastreamento de transtornos mentais nãopsicóticos. Os itens consistem em perguntas objetivas e respostas do tipo sim/não preenchidas pelo próprio docente. No seu cabeçalho estão instruções que explicitam ao analisado que ele deve responder as questões pensando nos últimos 30 dias. As questões foram lidas junto aos docentes e explicadas quando necessário. Este instrumento tem sido utilizado em vários países de culturas diferentes. (Gonçalves, Stein, \& Kapczinski, 2008).

As entrevistas foram gravadas por um dispositivo móvel e transcritas na íntegra, em seguida foram tratadas segundo a análise de conteúdo, do tipo análise categorial (Bardin, 2011). As respostas foram desmembradas em unidades/categorias e organizadas de acordo com a estrutura da entrevista, a saber: condições de trabalho; avaliação institucional; carga horária; relacionamento com os colegas de trabalho, gestores e alunos; autoavaliação do trabalho docente; adoecimento mental e/ou emocional relacionado ao trabalho docente.

Para a análise dos dados do questionário foi considerado o valor 1 para resposta afirmativa, somado no final para compor o escore. O ponto de corte do instrumento, de acordo com Harding et al. (1980), pode variar consideravelmente de acordo com o contexto cultural em que ele aplicado, no entanto, optamos por utilizar o ponto recomendado pelo teste. Este estabelece que um escore final maior ou igual a 7 comprova sofrimento mental.

Os dados da entrevista e do questionário foram organizados individualmente e depois cruzados para comparação dos escores com as verbalizações. Isto proporcionou um entendimento das implicações do processo de trabalho na saúde mental do docente. 
O presente estudo possui risco mínimo de acordo com as normas de pesquisa em saúde. A pesquisa foi apoiada pelo Programa de Iniciação Científica da Universidade Estácio de Sá UNESA- e foi submetida ao Comitê de Ética da mesma, tendo seu projeto sido aprovado sob o número 2.667.572. Todos os participantes assinaram o Termo de Consentimento Livre e Esclarecido (TCLE).

\section{RESULTADOS}

\section{Análise das entrevistas}

Do total de professores atingidos pela pesquisa, $81,8 \%$ eram mulheres e $18,2 \%$, homens, com idades entre 27 e 64 anos.

Todos têm formação inicial em psicologia, 5 possuem doutorado, 15 têm o título de mestrado e 2 possuem especialização lato sensu. Em relação ao tempo de atuação na UNESA, $31,8 \%$ possuem tempo de atuação <10 anos, sendo importante ressaltar que entre eles há um docente com 3 meses; 27,3\% possuem tempo de atuação $>10<20$ anos e 40,9\% possuem acima de 20 anos de carreira docente, com o tempo máximo de 36 anos.

\section{a) Condições de trabalho}

No que tange as condições de trabalho (materiais para as aulas, sala dos professores, estacionamento, entre outros), os dados coletados salientam a imprescindibilidade de melhores condições de trabalho referentes a infraestrutura dos materiais para as aulas, que dificultam de modo significativo o prosseguimento das mesmas.

Dos professores entrevistados, 59,1\% avaliaram as condições de trabalho como ruim/péssima. Estes salientam para uma necessidade de investimento em tecnologia, dentre os pontos citados está o fato de não haver datashow, computadores com internet, caixas de som e outros instrumentos de apoio às aulas previamente instalados em todas as salas. Relatam, também, a necessidade de melhoria no Sistema de Informações Acadêmicas (SIA), que é o ambiente on-line da Universidade onde professores fazem chamada, lançam presença ou falta dos alunos e também suas notas. Um dos entrevistados afirma "acredito que deveriam investir mais em tecnologias principalmente para as salas de aula. Hoje o professor precisa ficar andando para lá e para cá com datashow, pois eles não estão instalados nas salas. " (Sic). 
Outro, ainda sobre as condições de trabalho, alega "Bem precário. Muito ruim, falta material áudio/visual, ventilação... "(Sic)

Ademais, atribuem precariedade a infraestrutura do campus, evidenciando a ausência de infraestrutura aos banheiros, elevadores, climatização, organização de materiais, problema de gestão, falta de autonomia com o material didático, melhorias da privacidade na sala de coordenação e melhorias nos laboratórios. 27,3\% avaliam de forma positiva classificando-a como boa ou excelente. Outros $13,6 \%$ caracterizam-na como mediana, declarando que atende as necessidades.

\section{b) Avaliação Institucional}

Em 14 de abril de 2004 foi instituído, através da Lei $n^{\circ} 10.861$, o Sistema Nacional de Avaliação da Educação Superior - SINAES. Esse sistema surge com o objetivo de garantir a eficácia e melhoria na qualidade da educação superior.

O SINAES tem por finalidades a melhoria da qualidade da educação superior, a orientação da expansão da sua oferta, o aumento permanente da sua eficácia institucional e efetividade acadêmica e social e, especialmente, a promoção do aprofundamento dos compromissos e responsabilidades sociais das instituições de educação superior, por meio da valorização de sua missão pública, da promoção dos valores democráticos, do respeito à diferença e à diversidade, da afirmação da autonomia e da identidade institucional. (Lei 10.861, 2004, art. 1).

A Universidade Estácio de Sá, pautada nas normas e diretrizes previstas na lei supramencionada, desenvolveu a Comissão Própria de Avaliação - CPA, que foi avaliada e aprovada pelo Ofício-Circular INEP/DAES/nº 000081 de 07/07/05, segundo o histórico divulgado no site da própria instituição.

Seguindo este referencial, a Avaliação Institucional da UNESA é realizada semestralmente seguindo calendário acadêmico e envolve questões sobre o corpo docente, 0 corpo discente, avaliação dos cursos de graduação e a infraestrutura do Campus nas modalidades presencial e à distância.

Esse feedback é essencial, pois indica um norte para ações de melhoria na qualidade de ensino, sendo de responsabilidade da CPA encaminhar o relatório com os resultados aos Coordenadores dos Cursos de graduação, pós-graduação e setores administrativos. Esses resultados também são disponibilizados no Sistema de Informação Acadêmica (SIA) para que cada professor tenha acesso ao seu resultado de modo individual, compete aos coordenadores, apresentar e discutir esses resultados junto aos docentes privadamente. 
No que se refere a opinião dos docentes sobre os resultados da Avaliação Institucional, tomamos como ênfase os resultados do Índice de Satisfação do Aluno (ISA), sendo este, um instrumento de acompanhamento que exprime o nível de satisfação do aluno em relação aos seus professores e à Instituição.

Dos 22 professores entrevistados, 40,9\% dizem que o resultado do ISA os afeta tanto positiva quanto negativamente e dão bastante importância para esse resultado, em alguns discursos, os professores cobram certa consciência do aluno para realizar a avaliação que, em alguns casos, podem ser realizadas concentrando-se nas insatisfações pessoais que tem com o professor e não em seu propósito propriamente. Diz uma docente:

"Sei, acho que afeta a todos né. Eu recebo muitas críticas, as pessoas avaliam e elas avaliam com base num ponto que deixou de ganhar, se eu passar uma prova fácil fazem uma boa avaliação, mas se eu colocar uma prova difícil elas usam a avaliação pra criticar, quer dizer, eu acho que é uma ferramenta de gestão, um mecanismo de gestão da universidade válido, mesmo não concordando. " (Sic).

Apenas 18,2\% alegam de maneira clara não se afetarem com os resultados.

Foi citado que, turmas muito grandes são um grande desafio para o professor devido aos obstáculos que podem surgir, como por exemplo: o atraso dos alunos, dificuldade de se manter uma comunicação adequada e ruídos. Tais empecilhos podem fazer com que o resultado do ISA seja menor, devido a redução na qualidade da aula. Como diz o docente:

“Aqui nesse período deve ter 50 alunos... período passado tinha mais de 100. Então aqui agora 'ta' sendo muito mais tranquilo do que a disciplina de periodo passado. Provavelmente a minha avaliação agora vai ser melhor do que antes. Porque a partir do momento que você tem um aumento de pessoas você tem uma série de outras coisas. Você tem alunos que chegam no meio da aula, você tem alunos que não conseguem ficar sentados dentro de uma sala, você tem que se comunicar com eles é é muito mais difícil. Porque o aluno que 'ta' lá no fundo não te ouviu ou ele te ouviu, mas ele não guardou. A comunicação, os ruídos da comunicação, são muito maiores né. Então, enfim é bem complicado.... Então eu já sei que a minha avaliação... não saiu ainda, mas eu acho que vai ser melhor. " (Sic)

Quanto aos outros professores, 13,6\% não acessam o resultado do ISA, alguns afirmam que não o consideram válido, 9,1\% não conhecem ou não tiveram acesso a esse sistema de avaliação pois são novos na Universidade e $18,2 \%$ não responderam. 


\section{c) Carga horária}

Em relação a carga horária de trabalho não obtivemos, por parte da Universidade, a carga horária oficial de todos os professores. Foi considerado aquilo que foi relatado nas entrevistas.

Em 16 entrevistas, 56,25\% dos professores informam trabalhar mais de 30 horas semanais, sendo importante ressaltar que entre eles há dois docentes com carga horária de 60 horas por semana, pois além de atuar como docente, são também coordenadores de curso. $43,75 \%$ dos professores trabalham menos de 22 horas/semana. Em média, os docentes possuem uma carga horária aproximada de 32 horas/semana. Em virtude do trabalho docente se estender para além das salas de aulas, os docentes apresentaram certa dificuldade para responder à pergunta de maneira objetiva, em uma das entrevistas, o docente alega "Eu acho que são 44 horas ou 45 horas por aí. Entre 45 e 50. “(Sic). Outro ainda afirma, “Absurda, não tenho a mínima ideia, deve ser em torno de 40 horas... éeee duas, quatro, seis, sete, oito, nove, dez, onze, doze aí umas trinta horas semanais. " (Sic).

Os professores classificam sua carga horária como cansativa e com isto, sentem a necessidade de diminuí-la para que possam ter uma qualidade de vida melhor.

\section{d) Relacionamento com os colegas de trabalho, gestores e alunos}

O relacionamento entre os colegas de trabalho é avaliado de maneira positiva em $68,2 \%$ das entrevistas, que o caracterizam como tranquilo. Contudo, outros $31,8 \%$ avaliam como superficial, complicado e difícil. Estes apontam que sentem a necessidade de uma proximidade maior e alegam que não há criação de vínculos. Referem-se também a uma dificuldade de aceitação de professores novos pelos mais antigos e que, em virtude de o tempo ser corrido devido as funções da docência e das atividades fora do ambiente acadêmico, não há muito tempo para aproximação. Um docente alega:

"Ah, o relacionamento com os colegas de trabalho é na correria, temos pouco tempo 'pra' socializar. O profissional professor não fica alocado numa sala, ele chega bate o ponto e tem que ir dar aula, só se ele chegar cedo e ai dá 'pra' ficar um tempinho lá socializando, mas fora isso, às vezes eu to no consultório e tenho que sair de lá correndo 'pra' chegar aqui, bater o ponto e ir dar aula, ai não tem tempo praparar e conversar com ninguém. Mas isso é comum entre os professores. ” (Sic). 
Sobre o relacionamento com os gestores do Campus, 63,6\% dos entrevistados responderam que há pouco ou nenhum contato, alguns afirmam que não os conhecem ou que apenas os veem em algumas datas festivas, como dia do mestre. "Não acessa, algumas vezes em datas festivas e encontros pontuais, não sabe se é tão aberto, com os recentes não há bom dia nem boa noite. " (Sic).

Apenas 27,3\% caracterizaram com tranquilo, sendo importante frisar que dentre esses, há dois professores que são, também, coordenadores do curso. Um deles cita que passou a ter mais contato com os gestores após tornar-se coordenador. Além desses, 9,1\% referem-se aos que não responderam ou não entenderam a pergunta, referindo-se aos coordenadores do curso. Um professor enfatizou que acredita ser necessário uma aproximação dos gestores, já que o objetivo em comum é a educação e os professores estão na ponta desse processo.

Em relação ao relacionamento com os alunos, 63,6\% o caracterizam como bom, excelente, sem problemas ou dificuldades, mas, o tema desinteresse e desrespeito está presente em algumas das falas. Outros 36,4\% afirmam terem dificuldades, citam situações de desrespeito, desinteresse e falta de educação em sala de aula. No discurso dos docentes, é mencionado que há uma certa dificuldade em adequar a linguagem para dar aulas, já que alguns alunos possuem uma linguagem mais rica, enquanto outros, não. Outro afirma: "Com os alunos eu faço uso de uma estratégia, uma estratégia de distanciamento " (Sic). É comum no discurso dos professores observar certo desinteresse nos alunos pois citam a falta de compromisso e responsabilidade no que tange ao investimento e importância da formação profissional, um docente declara: "Falta de educação, falta de educação e respeito, acho que esse é o grande problema do aluno né, eu sou de uma época que quando o professor falava a gente calava a boca né. (Sic).

\section{e) Autoavaliação no trabalho docente}

No que se refere a auto avaliação como professor no quesito "expectativas alcançadas", $54,5 \%$ dos professores entrevistados avaliam de forma positiva, relatam que se sentem realizados e acreditam que suas expectativas foram alcançadas, alguns afirmam ter encontrado um ponto de paz ou ainda a satisfação ao ver seus alunos tendo sucesso no mercado de trabalho, um docente reconhece: "As expectativas alcançadas é olhar o mercado de trabalho e ver os alunos em áreas de sucesso. " (Sic). 13,6\% consideram-se na média mencionando a constante busca de melhorias e atualizações. $22,7 \%$ se autoavaliam de maneira negativa por não terem 
atingido aquilo que planejavam, além disso, alguns dos docentes declaram que a profissão é frustrante, mencionam o cansaço e decepção. Em uma das entrevistas, um docente admite

"Eu ainda me considero uma professora mediocre. Eu não me daria essa avaliação que a instituição e os alunos me dão. Eu me colocaria na média. Eu não me daria nota máxima, porque eu sempre acho que falta preparo. Eu nunca to preparada o suficiente. Eu acho que me falta profundidade. " (Sic).

Outros $9,1 \%$ não responderam a questão.

Quanto as expectativas a serem alcançadas, 31,8\% dos docentes falam sobre anseio em adquirir mais conhecimento e novas experiências, como por exemplo, fazer doutorado. 27,3\% falam do desejo em contribuir para a formação dos alunos, formar pessoas críticas, passar o seu legado, realizar pesquisas, bem como a contribuir na percepção dos alunos acerca da imprescindibilidade da terapia e entendimento da psicologia como ciência. 13,6\% exprimem desejo em obter reconhecimento e autonomia na área. 9,1\% falam sobre trabalhar menos ou sobre aposentadoria. 4,5\% afirmam já terem alcançado todas as suas expectativas. Outros, $13,6 \%$ não responderam à questão.

\section{f) Adoecimento mental e/ou emocional relacionado ao trabalho docente}

Com a finalidade de facilitar a compreensão dos resultados da entrevista, da análise dos dados foram criadas subcategorias desta categoria: 1) Alterações mentais/emocionais; 2) Adoecimento físico/fisiológico; e 3) Comportamentos para manutenção da saúde.

Os dados sinalizam para algum adoecimento no trabalho docente universitário da UNESA, Campus Nova Iguaçu. No que diz respeito a subcategoria Adoecimento físico/fisiológico (figura 1), os docentes apontam a presença de sintomas relacionados ao cansaço e desgaste físico, afecções osteomusculares como dores na coluna, no corpo e sobrecarga muscular, cefaleia e doenças otorrinolaringológicas (labirintite). Um dos docentes alega surgimento de doença autoimune e outro reconhece o surgimento de sintomas da Síndrome de Burnout:

"Eu desenvolvi uma doença autoimune. E uma das coisas que o médico falou foi que parasse diminuísse meu ritmo, minha carga horária. E ai eu zerei ela, expliquei 'pra' minha chefe que entendeu... e eu zerei a carga horária. Porque estava me afetando muito.... Tanto que o exame que estou indo fazer semana que vem e que por isso não darei aula 'pra' vocês, é consequência disso ainda. " (Sic).

Outro admite: 
"No início eu acho que tinha muitas doenças psicossomáticas. Minha imunidade era muito baixa, então eu vivia gripada, vivia adoecendo. E aí depois foi aumentando meu nível de estresse com essas indisposições e com a própria carga horária de trabalho. " (Sic).

Figura 1: Componentes da subcategoria Adoecimento físico/fisiológico.

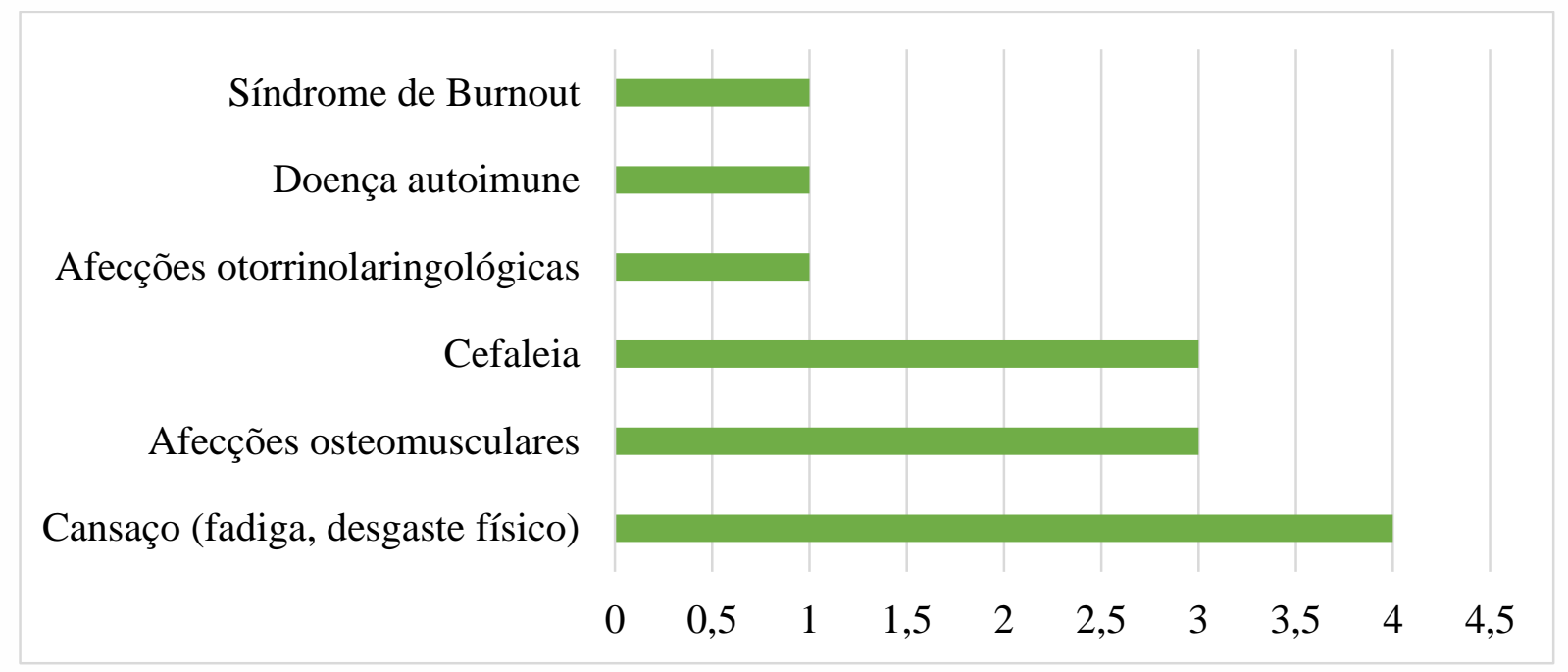

Fonte: Autores

No que tange a subcategoria Alterações mentais/emocionais (figura 2), foi possível constatar o alto índice de estresse, sendo destacado o período de provas como o de maior prejuízo. Apontam o excesso de obrigações da carreira como docente, a quantidade de alunos, junção dessas atividades com atividades fora do ambiente acadêmico e a carga horária densa. Também apontam desgaste emocional e cansaço mental, bem como o surgimento de doenças psicossomáticas. Um docente cita:

“Já tive uma grande depressão em 2014. Eu já estava trabalhando aqui e fiquei muito mal, foi um período muito difícil e eu não abri mão do período, nesse período eu fui muito mal avaliada, não sei da avaliação institucional, mas eu sei dos alunos, porque eu não consegui corresponder. Eu 'tava' muito doente né, e eu não quis tirar licença porque eu tinha um senso de responsabilidade muito grande.. Porque a minha primeira turma aqui na Estácio, a minha inauguração aqui na Estácio, eu me recordo bem, foi fevereiro de 2013. Eu entrei na sala 710 C e eu dei de cara com 113 alunos. Então até eu me adaptar..." (Sic). 
Figura 2: Componentes da subcategoria Alterações mentais/emocionais

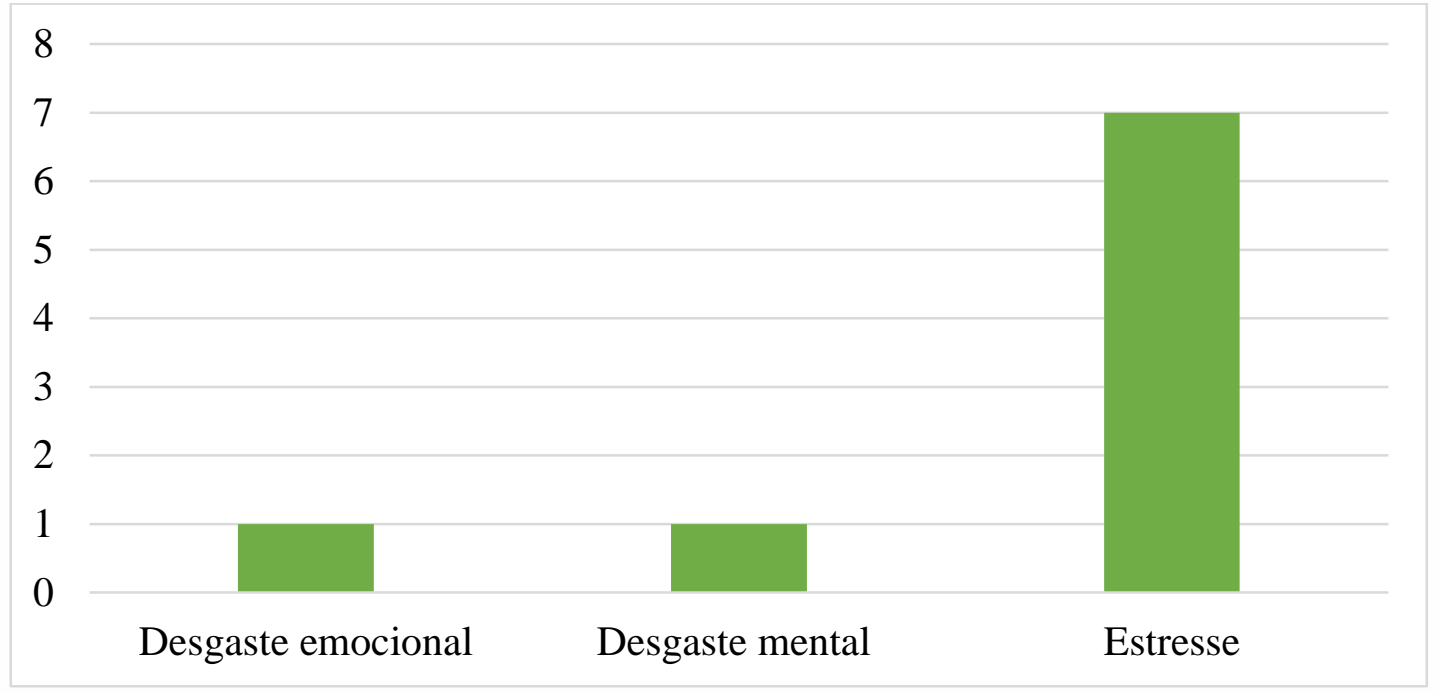

Fonte: Autores

Quanto ao conjunto Comportamentos para manutenção da saúde (figura 3), foi perguntado aos docentes se eles mantinham algum hábito saudável para manutenção da saúde mental, dos 22 professores entrevistados, 36,4\% afirmaram que praticam atividades físicas como pilates, corrida, caminhada, bicicleta, aeróbica, musculação, alongamento, relaxamento, academia, yoga e spinning, 36,4\% não praticam atividades físicas e 27,3\% não responderam. Em relação a tratamento psicoterapêutico/analítico, 81,8\% dos professores entrevistados declaram que fazem ou já fizeram terapia, desses mencionados, 33,3\% já fizeram terapia, mas no momento não o fazem mais. E, 18,2\%, não responderam à questão.

Figura 3: Componentes da subcategoria Comportamentos para manutenção da saúde.

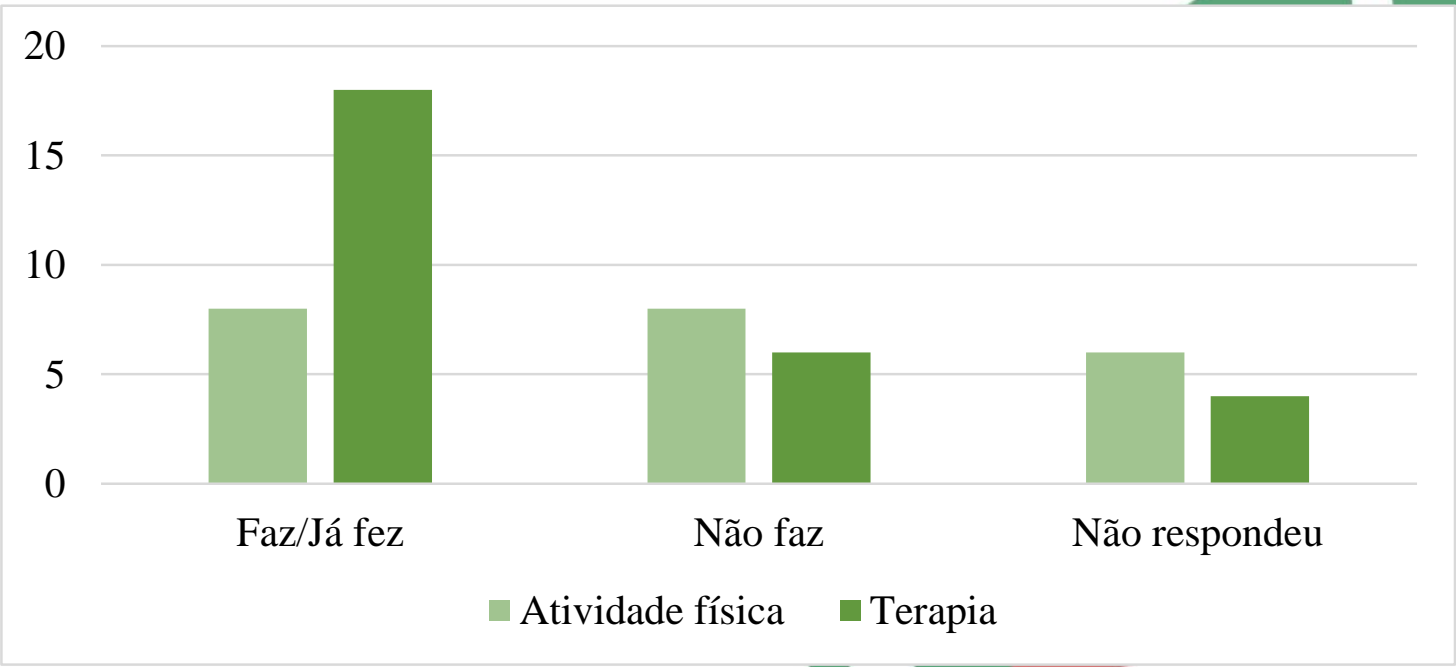

Fonte: Autores 


\section{ANÁLISE DO TESTE SRQ-20}

Dos 22 entrevistados, 22,7\% apresentam escore maior ou igual a 7. Analisando as perguntas do teste isoladamente (Tabela 1), percebe-se que em algumas afirmativas há uma predominância nas respostas. No que concerne a se sentir nervoso, tenso ou preocupado, em $54,5 \%$ dos casos, os docentes assinalaram afirmativamente a questão. Em 45,5\% dos casos, os docentes afirmam cansar-se com facilidade, ademais, 36,4\% confirmam que se sentem cansados durante a maior parte do tempo.

Referente a ter uma qualidade ruim de sono, há uma prevalência em 31,8\% dos casos, sendo importante ressaltar que, em dois casos, os docentes não marcaram nenhuma das alternativas, contudo, a especificaram como "em alguns momentos" ou "pouco". O mesmo resultado é obtido a respeito da dificuldade em realizar satisfatoriamente as atividades diárias.

Tabela 1: Desempenho de cada item de rastreamento do Self-Reporting Questionnaire

\begin{tabular}{|l|c|}
\hline Itens do SRQ-20 & Total \\
\hline Você tem dores de cabeça frequente? & $(\%)$ \\
\hline Tem falta de apetite? & 27,3 \\
\hline Dorme mal? & 4,5 \\
\hline Assusta-se com facilidade? & 31,8 \\
\hline Tem tremores nas mãos? & 9,1 \\
\hline Sente-se nervoso (a), tenso (a) ou preocupado (a)? & 9,1 \\
\hline Tem má digestão? & 54,5 \\
\hline Tem dificuldades de pensar com clareza? & 22,7 \\
\hline Tem se sentido triste ultimamente? & 13,6 \\
\hline Tem chorado mais do que o de costume? & 13,6 \\
\hline Encontra dificuldades para realizar com satisfação suas atividades diárias? & 9,1 \\
\hline Tem dificuldades para tomar decisões? & 31,8 \\
\hline Tem dificuldades no serviço (seu trabalho é penoso, lhe causa sofrimento?) & 9,1 \\
\hline É incapaz de desempenhar um papel útil em sua vida? & 13,6 \\
\hline Tem perdido o interesse pelas coisas? & 9,1 \\
\hline Você se sente uma pessoa inútil, sem préstimo? & 13,6 \\
\hline
\end{tabular}




\begin{tabular}{|l|c|}
\hline Tem tido ideia de acabar com a vida? & 0 \\
\hline Sente-se cansado (a) o tempo todo? & 36,4 \\
\hline Você se cansa com facilidade? & 45,5 \\
\hline Tem sensações desagradáveis no estomago? & 27,3 \\
\hline
\end{tabular}

Fonte: Autores

Analisando as perguntas do teste isoladamente (Tabela 1), percebe-se que em algumas afirmativas há uma predominância nas respostas. No que concerne a se sentir nervoso, tenso ou preocupado, em 54,5\% dos casos, os docentes assinalaram afirmativamente a questão.

Em 45,5\% dos casos, os docentes afirmam cansar-se com facilidade, ademais, 36,4\% confirmam que se sentem cansados durante a maior parte do tempo.

Referente a ter uma qualidade ruim de sono, há uma prevalência em 31,8\% dos casos, sendo importante ressaltar que, em dois casos, os docentes não marcaram nenhuma das alternativas, contudo, a especificaram como "em alguns momentos" ou "pouco". O mesmo resultado é obtido a respeito da dificuldade em realizar satisfatoriamente as atividades diárias.

\section{DISCUSSÃO}

A ausência de materiais de apoio às aulas e de uma boa infraestrutura atua como um expoente contribuinte para o desgaste físico e emocional, pois, os docentes acabam precisando estender o trabalho para além das salas de aula, buscando estratégias pedagógicas na tentativa de suprir à falta de instrumentos. Os docentes mobilizam as suas capacidades físicas, cognitivas e afetivas para que seja possível alcançar os objetivos da produção escolar e, essa dinâmíca, em consonância com condições de trabalho deficientes, podem gerar sobre-esforço ou hipersolicitação de suas funções psicofisiológicas, sendo este um dos motivos de afastamento do trabalho. (Gasparini, Barreto \& Assunção, 2005). Os dados aqui apresentados se assemelham ao encontrado em diversos estudos na literatura que comparam as condições de trabalho com as repercussões na saúde física e mental do profissional da educação. Nas produções científicas é apontado dor de garganta, dor nas pernas, dor nas costas, rouquidão, cansaço mental e dores no corpo relacionadas ao esforço excessivo como algumas das queixas mais frequentes (Reis et al., 2006; Cortez et al. 2017). Conforme afirmado por Reis et al. (2006), ensinar é uma tarefa extremamente estressante e provoca, consequentemente, repercussões na saúde física, mental e no desempenho profissional dos docentes. A dupla jornada de trabalho, o excesso de tarefas, 
ausência de controle em sala de aula, ruídos, problemas institucionais, excesso de alunos e infraestrutura ineficiente, são fatores, citados por Cortez et al. (2017), como contribuintes de sintomas físicos e psíquicos, como estresse, irritabilidade, Síndrome de Burnout, nervosismo, exaustão e distúrbios de voz.

\section{CONSIDERAÇÕES FINAIS}

A saúde do professor tem fomentado interesse na comunidade científica, pois é considerada uma das profissões mais estressantes da contemporaneidade. Diferentes pesquisas apontam que o trabalho docente facilita o desenvolvimento de sofrimento psíquico, apontando para um risco de estes sofrerem desgaste físico, mental e emocional devido as condições de trabalho.

O presente estudo, tendo como base a análise dos dados colhidos, atingiu a proposta de evidenciar as relações entre o trabalho docente e as condições de surgimento do adoecimento, especialmente o mental, que afligem os docentes da Universidade Estácio de Sá, Campus Nova Iguaçu.

A partir da correlação entre os dados da entrevista e do SRQ-20, foi possível constatar a presença de adoecimento mental em professores do curso de Psicologia da Universidade Estácio de Sá, Campus Nova Iguaçu.

O trabalho docente e as condições de trabalho corroboram para o surgimento de sintomas psicossomáticos, desgaste emocional/mental, estresse, cansaço, dores de cabeça, doenças osteomusculares e otorrinolaringológicas, doenças autoimunes e sintomas da Síndrome de Burnout. Além disso, os docentes apontam uma má qualidade de sono, cansaço excessivo, nervosismo e preocupação excessiva. Apontando assim a necessidade de desenvolver políticas de promoção a saúde desses profissionais.

$\mathrm{Na}$ Psicologia as formações pessoal e profissional de uma pessoa estão intimamente ligadas. O psicólogo lida com a subjetividade do outro a partir da sua própria subjetividade. Os docentes de psicologia dedicam-se a ensinar aos seus alunos a lidarem com a saúde mental, para tanto, ressaltamos a primordialidade da promoção e manutenção de sua própria saúde mental para assim estar disponível ao outro que necessita do seu tratamento ou conhecimento.

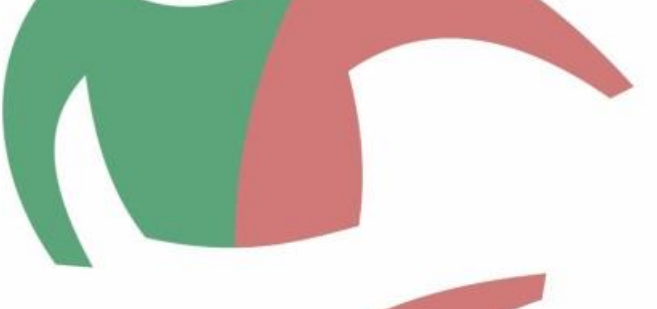




\section{REFERÊNCIAS}

Bardin, L. (2011). Análise de conteúdo. (ed. 70). São Paulo.

Cavichioli, R. G. C. (2010). Sociedade do conhecimento: a educação como pilar. Revista de Educação, 13(15), 141-154. Recuperado em 02 de abril de 2018, de http://www.pgsskroton.com.br/seer/index.php/educ/article/view/1871/1776

Cerchiari, E. A. N., Caetano, D., \& Faccenda, O. (2005). Prevalência de transtornos mentais menores em estudantes universitários. Estudos de Psicologia (Natal), 10(3), 413420. https://dx.doi.org/10.1590/S1413-294X2005000300010.

Cortez, P. A., Souza, M. V. R., Amaral, L. O., \& Silva, L. C. A. (2017). A saúde docente no trabalho: apontamentos a partir da literatura recente. Cadernos Saúde Coletiva, 25(1), 113 122. Epub March 30, 2017.https://dx.doi.org/10.1590/1414-462x201700010001.

Costa, L. S. T., Gil-Monte, P. R., Possobon, R. F., \& Ambrosano, G. M. B. (2013). Prevalência da Síndrome de Burnout em uma amostra de professores universitários brasileiros. Psicologia: Reflexão e Crítica, 26(4), 636642. https://dx.doi.org/10.1590/S0102-79722013000400003.

Decreto n. 95.741, de 19 de Fevereiro de 1988. Autoriza o funcionamento do curso de Psicologia das Faculdades Integradas Estácio de Sá, no Rio de Janeiro. Recuperado de: https://www.lexml.gov.br/urn/urn:lex:br:federal:decreto:1988-02-19;95741

Diehl, L., \& Marin, A. H. (2016). Adoecimento mental em professores brasileiros: revisão sistemática da literatura. Estudos Interdisciplinares em Psicologia, 7(2), 64-85. Recuperado em 02 de abril de 2018, de http://pepsic.bvsalud.org/sc ielo.php?script=sci_arttext\&pid=S2236-640720160002000 05\&lng=pt\&tlng=pt

Estácio. (n/d) Retrieved July 17, 2019, from Portal Estácio: http://portal.estacio.br/unidades/universidade-estácio-de-sá/cpa-avaliaçãoinstitucional/histórico-da-cpa/

Gasparini, S. M., Barreto, S. M., \& Assunção, A. Á. (2005). O professor, as condições de trabalho e os efeitos sobre sua saúde. Educação e Pesquisa, 31(2), 189199. https://dx.doi.org/10.1590/S1517-97022005000200003.

Gonçalves, D. M., Stein, A. T., \& Kapczinski, F. (2008). Avaliação de desempenho do SelfReporting Questionnaire como instrumento de rastreamento psiquiátrico: um estudo comparativo com o Structured Clinical Interview for DSM-IV-TR. Cadernos de Saúde Pública, 24(2), 380-390. https://dx.doi.org/10.1590/S0102-311X2008000200017

Harding, T.W., Arango, M. V., Baltazar, J., Climent, C. E., Ibrahim, H. H. A., Ladrido-Ignacio, L., . . . Wig, N. N. (1980). Mental disorders in primary health care: a study of their frequency and diagnosis in four developing countries. Psychological Medicine, 10, 23141. Recuperado em 05 de abril de 2018, de https://www.ncbi.nlm.nih.gov/pubmed/738 4326 
Jennings, P. A., \& Greenberg, M. T. (2009).The prosocial classroom: Teacher social and emotional competence in relation to student and classroom outcomes. Review of Educational Research, 79(1), 491-525. Recuperado em 05 de abril de 2018, de http://bottemabeutel.com/wpcontent/uploads/2014/01/Jennings-Greenberg_Teachersocial-and-emotionalcompetence

Lei n. 4.119, de 27 de agosto de 1962. Dispõe sobre cursos de formação em Psicologia e regulamenta a profissão de psicólogo. Brasília: Presidência da República; Casa Civil; Subchefia para Assuntos Jurídicos, 2007. Recuperado de: http://www.planalto.gov.br/ccivil_03/leis/1950-1969/L4119.htm

Lei n. 10.861, de 14 de abril 2004. Institui o Sistema Nacional de Avaliação da Educação Superior - SINAES e dá outras providências. Recuperado de: http://www.planalto.gov.br/ccivil_03/_ato2004-2006/2004/lei/110.861.htm

León, G. L. (2011). Los profesionales de secundaria, como factores de riesgo en el síndrome de Burnout. Revista Electrónica Educare, 15(1), 177-191. Recuperado em 05 de abril de 2018, de https://dialnet.unirioja.es/descarga/articulo/3683617.

Lipp, M. N. (2008). Mecanismos Neuropsicofisiológicos Do Stress - Teoria E Aplicações Clínicas. Brasil: Casa do Psicólogo.

Organização Internacional do Trabalho. (1984) A condição dos professores: A condição dos professores recomendação Internacional de 1966, um instrumento para a melhoria da condição dos professores. Genebra, OIT/ Unesco.

Portaria n. 1942, de 25 de outubro de 1991. (1991, 29 outubro). Diário Oficial da União, Rio de Janeiro.

Reis, E. J. F. B., Araújo, T. M., Carvalho, F. M., Barbalho, L., \& Silva, M. O. (2006). Docência e exaustão emocional. Educação \& Sociedade, 27(94), 229-253. https://dx.doi.org/10.1590/S0101-73302006000100011.

Silva, E. P. (2015). Adoecimento e sofrimento de professores universitários: dimensões afetivas e ético-políticas. Psicologia: teoria e prática, 17(1), 61-71. Recuperado em 05 de abril de 2018, de http://pepsic.bvsalud.org/scielo.php?script=sci_arttext\&pid=S1516$36872015000100006 \& \operatorname{lng}=p t \& \operatorname{tlng}=p t$ 